\title{
PROBLEMAS ÉTICOS NO CUIDADO AO PACIENTE CRÍTICO
}

\author{
Andréia Cerri ${ }^{1}$, Hellen Roehrs², Karla Crozeta ${ }^{3}$, Leila Maria Mansano Sarquis ${ }^{4}$, Ligia Palu ${ }^{5}$
}

\begin{abstract}
RESUMO: No atendimento ao paciente crítico a dramaticidade das situações torna a resolução dos problemas um ato complexo. Assim, o objetivo do estudo foi identificar os principais problemas éticos vivenciados pela enfermagem no cuidado ao paciente crítico hospitalizado. Pesquisa descritiva, de abordagem qualitativa, com coleta de dados por meio de entrevista a 20 profissionais de enfermagem de uma unidade de urgência e emergência de um hospital de ensino em Curitiba/PR, de janeiro a março de 2010, as quais foram analisadas pela análise temática. Verificou-se: a falta de humanização no cuidado; dificuldade na comunicação da equipe multidisciplinar; quebra do sigilo profissional; formas inapropriadas de comunicação; dificuldades relacionadas ao direito de decisão; dificuldade na distribuição adequada de recursos na assistência; limitação financeira do paciente e da família que implica no cuidado. O reconhecimento desses problemas representa um primeiro passo de problematizar, sensibilizar e refletir a partir da percepção dos problemas éticos.
\end{abstract}

PALAVRAS-CHAVE: Ética baseada em princípios; Enfermagem; Cuidados críticos.

\section{ETHICAL PROBLEMS IN THE CARE OF THE CRITICALLY-ILL PATIENT}

ABSTRACT: In attending the critically-ill patient, the dramaticity of the situation turns the resolution of problems into a complex act. This being so, this study aimed to identify the principal ethical problems experienced in nursing in the care of the critically-illpatient in hospital. It is descriptive research with a qualitative approach, with data analyzed through thematic analysis following collection via interviews with twenty nursing professionals in an accident and emergency unit in a teaching hospital in Curitiba, in the Brazilian state of Paraná, between January and March of 2010. The study notes: a lack of humanization in care, difficulties in communication among the multidisciplinary team, breaches of professional confidentiality, inappropriate forms of communication, difficulties relating to the right to decide, difficulty in the appropriate allocation of resources in the provision of care and the negative impact on patient care of the patient's and their family's financial limitations. The recognition of these problems represents the first step to problematizing, sensibilitizing and reflecting, based on the perception of ethical problems. KEYWORDS: Principle based ethics; Nursing; Critical care.

\section{PROBLEMAS ÉTICOS EN EL CUIDADO AL PACIENTE CRÍTICO}

RESUMEN: En el atendimiento al paciente crítico la dramaticidade de las situaciones hace de la resolución de los problemas algo complexo. Así, el objetivo del estudio fue identificar los principales problemas éticos experenciados por la enfermería en el cuidado al paciente crítico hospitalizado. Investigación descriptiva, de abordaje cualitativo, cuyos datos fueron recogidos por medio de entrevista a 20 profesionales de enfermería de una unidad de urgencia y emergencia de un hospital de enseñanza en Curitiba/PR, de enero a marzo de 2010, los cuales fueron analizados por análisis temático. Se ha verificado: falta de humanización en el cuidado; dificultad en la comunicación del equipo multidisciplinar; quiebra del sigilo profesional; formas inadecuadas de comunicación; dificultades acerca del direcho de decisión; dificultad en la distribucción adecuada de recursos en la asistencia; limitación financieira del paciente y de la familia que implica en el cuidado. El reconocimiento de eses problemas representa un primero paso para problematizar, sensibilizar y reflexionar a partir de la percepción de los problemas éticos.

PALABRAS-CLAVE: Ética basada en principios; Enfermería; Cuidados críticos.

${ }^{1}$ Enfermeira. Residente em Saúde da Família da Universidade Federal do Paraná - UFPR.

${ }^{2}$ Enfermeira. Mestre em Enfermagem. Professora do Departamento de Enfermagem - DENF UFPR. Membro do Núcleo de Estudo, Pesquisa e Extensão em Cuidado Humano de Enfermagem - NEPECHE. Conselheira Tesoureira do Conselho Regional de Enfermagem do Paraná. ${ }^{3}$ Enfermeira. Mestre em Enfermagem. Doutoranda em Enfermagem pelo Programa de Pós-Graduação em Enfermagem - PPGENF UFPR. Membro do Grupo de Pesquisa Tecnologia e Inovação em Saúde: Fundamentos para a Prática Profissional - TIS.

${ }^{4}$ Enfermeira. Doutora em Enfermagem. Professora do DENF e do PPGENF UFPR. Membro do Grupo de Estudo Multiprofissional em Saúde do Adulto - GEMSA e do Grupo de Pesquisa de Qualidade de Vida da EEUSP.

${ }^{5}$ Enfermeira do Centro de Terapia Intensiva Adulto do Hospital de Clínicas da UFPR. Especialista em Enfermagem do Trabalho.

Autor correspondente:

Recebido: 21/02/11

Andréia Cerri

Aprovado: 16/08/11

Universidade Federal do Paraná

R. Nelson Ferreira da Luz, 431 - 81220-130 - Curitiba-PR-Brasil

E-mail: andreia_cerri@hotmail.com 


\section{INTRODUÇÃO}

Nas unidades de Pronto-Atendimento e de Terapia Intensiva, o caráter de urgência e a dramaticidade das situações fazem com que os problemas éticos sejam mais intensos quando comparados a outras unidades de atendimento. Nesse sentido, em alguns momentos, deliberar e decidir sobre o tipo de assistência à saúde torna-se uma tarefa árdua, principalmente quando os profissionais se deparam com os limiares críticos e tênues da vida dos pacientes hospitalizados. Desse modo, atitudes reflexivas e fundamentadas em princípios éticos contribuem para uma assistência efetiva e humanizada.

A palavra ética, do grego ethos, refere-se aos costumes, à conduta e às regras de comportamento da sociedade, preocupando-se com o agir humano, com os comportamentos cotidianos e com as opções existenciais. A ética é compreendida como um ramo da filosofia prática, que tem como propósito refletir sobre as ações do homem e suas finalidades, e estudar os conflitos entre aquilo que podemos considerar como moralmente justificável e aquilo que não pode ser assim considerado ${ }^{(1)}$.

A Enfermagem, como profissão regulamentada pelo Estado, é orientada por normas e princípios contidos na Lei do Exercício Profissional da Enfermagem, Lei 7.498/1986(2) e no Código de Ética dos Profissionais de Enfermagem (CEPE) - Resolução 311/2007 do Conselho Federal de Enfermagem $\mathrm{COFEN}^{(3)}$. A Enfermagem compromete-se com a qualidade de vida e com a saúde do paciente e sua família. As ações profissionais devem ser executadas com responsabilidade, com princípios na tomada de decisão e atitudes nos cuidados a pacientes críticos. Essa clientela requer a defesa dos princípios éticos que assegurem o acesso à saúde, com justiça e equidade, a autonomia e a dignidade no atendimento, em busca dos possíveis benefícios terapêuticos (beneficência e não-maleficência).

Um problema ético abrange aspectos, questões ou implicações éticas de ocorrências comuns, corriqueiras na prática da atenção à saúde, não configurando, necessariamente, um dilema ${ }^{(4)}$. Uma situação para ser considerada um dilema, deve envolver duas proposições contraditórias, entre as quais o indivíduo encontra-se na obrigação de escolher. Por extensão de seu sentido etimológico, a expressão dilema é aplicada quando há oposição mútua de duas teses filosóficas, sendo a aceitação de uma delas leva à negação ou à afirmação da outra hipótese sem que nenhuma das duas possa ser refutada ${ }^{(5)}$

Nesse sentido, cabe ao enfermeiro e aos profissionais de enfermagem questionar, refletir e debater os pontos polêmicos, como participantes ativos na busca de soluções de problemas que ocorrem no cotidiano do seu trabalho(6).

Nesse contexto, o objetivo dessa pesquisa foi identificar os principais problemas éticos vivenciados pela enfermagem no cuidado ao paciente crítico hospitalizado. Não foram incluídos nos resultados as situações que configuraram situações consideradas dilemas éticos, o que constituiu um outro estudo realizadas pelos autores.

\section{METODOLOGIA}

Esta pesquisa foi precedida pela aprovação do Comitê de Ética do Hospital em que foi realizada, sob o protocolo n. 2032.199/2009-09, por atender a Resolução n. 196/1996(7) do Conselho Nacional de Saúde, que trata de pesquisa envolvendo seres humanos.

Trata-se de uma pesquisa descritiva, de abordagem qualitativa, que permite trabalhar com o universo de significados, motivos, valores e atitudes, o que corresponde a um espaço mais profundo das relações e dos fenômenos estudados ${ }^{(8)}$.

O local do estudo foi uma unidade de Urgência e Emergência de um hospital de ensino em CuritibaPR, e a técnica de coleta de dados empregada foi a entrevista semiestruturada. Os sujeitos do estudo foram profissionais da equipe de enfermagem da referida unidade de Urgência e Emergência, sendo incluídos os profissionais que aceitaram participar do estudo. O número de sujeitos participantes da pesquisa não foi pré-determinado, de modo que as entrevistas foram encerradas quando se percebeu a saturação de informações.

Desse modo, os sujeitos da pesquisa foram 20 profissionais, sendo 8 enfermeiros, seis técnicos e seis auxiliares de enfermagem, cuja faixa etária variou de 27 a 44 anos e a experiência profissional com pacientes críticos foi de dois a 20 anos. Todos os participantes do estudo expressaram sua concordância por meio da assinatura do Termo de Consentimento Livre e Esclarecido, nos moldes estabelecidos pela Resolução n. 196/1996 ${ }^{(7)}$.

A coleta de dados ocorreu no período de janeiro 
a março de 2010. A entrevista semiestruturada foi composta por duas questões centrais. Primeiramente, foi solicitado ao profissional para que narrasse uma situação que considerou como um problema ético vivenciado no cuidado ao paciente crítico, e a segunda questão solicitou que definisse o que é problema ético. Realizou-se uma única entrevista com cada profissional participante, totalizando 20 entrevistas.

A fim de preservar a identidade dos participantes, foi estabelecido o código "E" para designar os entrevistados, de modo que o entrevistado número 1 ficou identificado pelo código "E1" e assim, sucessivamente, até o código "E20". A codificação dos sujeitos foi utilizada na análise dos discursos apresentados pelos membros da equipe de enfermagem, mantendo esta ordem em todo o processo de organização e análise das informações obtidas.

Empregou-se o referencial de análise temática, o qual permite identificar, nas falas dos entrevistados, os núcleos de sentido que as compõem e evidenciar a presença ou frequência de significado para o objetivo analítico do estudo ${ }^{(8)}$. Dessa forma, a análise dos dados baseou-se na codificação dos entrevistados e abrangeu três etapas, a partir da transcrição dos conteúdos: pré-análise, exploração do material e tratamento dos resultados.

Esta pesquisa foi precedida pela aprovação no Comitê de Ética do Hospital em que foi realizada, sob o protocolo n. 2032.199/2009-09, por atender a Resolução n. 196/1996(7) do Conselho Nacional de Saúde, que trata de pesquisa envolvendo seres humanos.

\section{RESULTADOS}

Os dados obtidos permitiram identificar os principais problemas éticos e bioéticos vivenciados no cuidado: a falta de humanização no cuidado; dificuldades na comunicação da equipe multidisciplinar; quebra do sigilo profissional, comentários e exposição no ambiente crítico; formas inapropriadas de comunicação com o paciente e com a família - desrespeito ao direito à informação; dificuldades relacionadas ao direito de decisão do paciente e da familia; dificuldade na distribuição adequada de recursos na assistência; limitações financeiras do paciente e da família e sua implicação no cuidado, os quais são explicitados a seguir.

\section{A falta de humanização do cuidado}

Dentre os problemas éticos descritos pelos participantes da pesquisa, a falta de humanização foi apontada, conforme identificada neste depoimento:

Tem muito comportamento, do próprio profissional mesmo, que acho, que já começa devido há muito tempo já estar trabalhando. Principalmente quem trabalha com paciente crítico, acaba banalizando a morte, a pessoa [...] digamos assim, a pessoa parou num quarto, que aqui acontece muito, direto,e dai você não tem mais aquela sensação [...] perde a noção de que tem aquele momento ali, de morte. (E5)

O fato relatado, em algumas falas, é compreendido como uma atitude que interfere no bem-estar e no comprometimento da qualidade de vida do paciente terminal hospitalizado e, desta forma, é categorizado como uma violação à beneficência:

E ela gemente, sofrendo, tudo bem, depois de três horas ela morreu, mas eu achei que ela sofreu tanto pra morrer! Isso pra mim é um problema. Daí, então eu cheguei, a gente puncionou a veia, colocou sedativo, mas eu achei que ela sofreu demais. E a gente não pode achar que isso é normal. É normal a morte, mas não acho normal o sofrimento, e dentro de uma estrutura hospitalar! (E20)

\section{Dificuldades na comunicação da equipe multi- disciplinar}

Os participantes da pesquisa apontam que a ineficiência na comunicação faz com que ocorra infração dos princípios da beneficência e não-maleficência, pois as decisões, por vezes, não são tomadas adequadamente ou em conjunto, influenciando diretamente no cuidado de enfermagem:

Às vezes, quando uma pessoa fala uma coisa, e quando você, chega à tarde, outro fala diferente. Pra mim, isso é um dilema, de se ter opiniões diferentes para o mesmo paciente. Às vezes, não se chega num consenso. (E15)

[...] você as vezes acha que tem que investir, ou não.Você acha que já deu alí, e outro profissional continua investindo. (E17) 
Quebra de sigilo profissional, comentários e exposição do paciente no ambiente crítico

As falas dos entrevistados chamaram a atenção para a frequência com que ocorrem comentários inapropriados por parte de profissionais de saúde no ambiente crítico. A maioria dos participantes da pesquisa citou essa situação como um problema ético, uma vez que pode causar desconforto a pacientes e familiares, bem como prejuízo ao cuidado prestado.

Quando os comentários ocorrem de forma inadequada, considera-se que constitui uma violação ao dever ético de não causar dano. Essa situação é representada pelas falas seguintes:

Teve uma situação que ocorreu semana passada, que eu achei que, foi assim, um absurdo o que um residente comentou dentro do box de um paciente consciente. Realmente, era um paciente grave, que a gente não tinha esperança que ele sobrevivesse. Só que, assim, apesar da gravidade dele, ele estava consciente e o residente simplesmente falou: "Ah vai morrer mesmo", e o paciente ouviu aquilo. (E16)

O que acontece aqui, bastante, aqui na nossa unidade, é a passagem de plantão dos médicos, no qual é falado dos quinze pacientes que temos internados. Então, todos escutam particularidades de cada paciente. (E5)

Formas inapropriadas de comunicação com o paciente e com a família - desrespeito ao direito à informação

Os profissionais entrevistados apontaram que, quando a informação sobre a situação do paciente não é transmitida de forma apropriada, deparam-se com um problema ético no cuidado, o que constitui uma violação ao princípio da autonomia do paciente:

[...] a discussão toda é em função do paciente, mas ele nunca está participando. Eu acredito ser isso um problema ético. Então, falam termos técnicos, de difícil entendimento para a pessoa [...], por exemplo, "prognóstico fechado", ou falam que não tem muita perspectiva de "tratamento positivo". Nós percebemos que o paciente passa a ser um objeto, em vez de ser alguém que está sendo cuidado. (E11)

Às vezes, acaba não sendo ético, porque a gente não traz respeito a isso; a gente, às vezes, é desrespeitoso, porque você tem que partir também do que o outro quer, né? Da necessidade do outro e ver se a gente está respeitando aquilo. Muitas vezes, a gente toma atitudes e a gente toma sem avaliar muito o que o outro quer também. (E20)

\section{Dificuldades relacionadas ao direito de decisão do paciente e da família}

No contexto do ambiente crítico, os profissionais se deparam com o fato de constantemente se relacionarem com a família e com seu direito de decidir pelo paciente. É a família que representa a autonomia da pessoa que está sem condições de exercê-la, como no caso de muitos pacientes hospitalizados nas unidades de cuidados críticos:

A família diz: "não quero que entube, não quero que faça nada, só quero que diminua o sofrimento, que tire a dor, principalmente". E ai os médicos residentes nessa ânsia de "eu tenho que aprender, eu tenho que fazer, eu não posso deixar morrer", vai lá e entuba o paciente, põe medicação, coloca drogas acentuadas. (E6)

Eu penso, assim, que nessa questão ética aqui tem que sentar e decidir com a família, para que a família decida o que é melhor. Mas nem sempre isso acontece. (E19)

\section{Dificuldade na distribuição adequada de recursos na assistência}

Nas falas dos entrevistados, percebe-se como é difícil proceder nas questões relacionadas a leitos disponíveis, procedimentos e investimentos na assistência.

Uma determinada pessoa falou: "Ah ela vai morrer mesmo, prá que ficar investindo?". Isso pra mim é um problema ético, um problema de consciência ética de cada um. "Por que que eu vou tratar a ferida dela se ela vai morrer mesmo? Por que que eu vou usar o meu curativo mais caro nela se ela vai morrer mesmo?". Mas ela está aqui! (E17)

Um paciente com a pressão de seis por dois, pulso não aferível, instável e coisa a mais, pra que aumentar droga vasoativa? Prá que usar tantos recursos, antibióticos e essas coisas? (E6) 


\section{DISCUSSÃO}

A ética exige a reflexão das condutas embasada em princípios, valores, direitos e deveres que norteiam o trabalho dos profissionais de saúde, como elemento fundamental para inserir a dimensão humana no cuidado, nas relações profissionais e no processo de intervenção interdisciplinar da saúde ${ }^{(9)}$.

\section{A falta de humanização no cuidado}

O cuidado deve ser um ato de atenção e auxílio na busca de dignidade ao ser humano debilitado. Nas falas dos participantes, foi possível identificar como, às vezes, são conduzidas determinadas ações pela equipe que podem levar à falta de humanização do cuidado. A Constituição Federal Brasileira, em seu artigo $1^{\circ}$, inciso III, assinala a dignidade da pessoa humana como um dos fundamentos do Estado ${ }^{(11)}$, bem como o CEPE, quando explicita seus princípios fundamentais, dispõe que o profissional de enfermagem deve respeitar a vida, a dignidade e os direitos humanos, em todas as suas dimensões ${ }^{(3)}$.

Ao profissional, é importante uma reavaliação do cuidado prestado para que se possa ressaltar que os preceitos éticos devem sempre nortear a profissão. O respeito ao paciente é imprescindível, a fim de que o cuidado não seja concebido apenas como a aplicação de técnicas, mas sim uma prática complexa que contemple o indivíduo que recebe esse cuidado como um ser digno, com necessidades biológicas, psicológicas, sociais e espirituais ${ }^{(11)}$.

Os profissionais entrevistados perceberam que o cuidado de enfermagem é contínuo, pois não se limita ao processo de cura. Identificaram que, no dia a dia de trabalho, é possível se defrontar com o problema da falta de humanização em relação ao cuidado do paciente em fase terminal, e compreendem que os cuidados paliativos devem ser fundamentados no conforto e na diminuição do sofrimento o máximo possível, mas infelizmente nem sempre isso acontece.

No contexto do cuidado paliativo, mesmo quando há conhecimento da terminalidade da vida e o paciente não tem indicação de intervenções cirúrgicas e outras práticas terapêuticas, ainda assim tem muito a ser feito por esse cliente e sua família, do ponto de vista humano e ético, especialmente para a Enfermagem, à qual cabe promover o conforto e diminuir ao máximo o sofrimento dessa pessoa, assegurando-lhe um morrer com mais dignidade ${ }^{(12)}$.

\section{Dificuldades na comunicação da equipe multi- disciplinar}

Para que o paciente receba uma assistência adequada, na qual sejam respeitados os princípios da beneficência e não-maleficência, é fundamental uma comunicação bem sucedida entre os elementos da equipe de saúde, como uma atitude interdisciplinar. Nesse sentido, considera-se a comunicação efetiva da equipe como uma atitude coletiva em benefício da pessoa que está sendo cuidada.

A comunicação e o relacionamento profissional refletem o empenho da equipe de enfermagem em favor do paciente. A rotina do trabalho da Enfermagem exige uma interação contínua com profissionais da equipe multiprofissional para direcionar sua própria atuação, bem como para o seguimento do cuidado ao paciente ${ }^{(12)}$.

Dentro de um ambiente hospitalar, essa comunicação entre os profissionais é fator indispensável à interdisciplinaridade na busca da superação das fronteiras disciplinares. Pode-se construí-la por meio da percepção dos pontos comuns entre as disciplinas em níveis de integração, com base na síntese de conhecimentos científicos ou no estabelecimento de uma linguagem interdisciplinar consensualmente construída, em benefício aos pacientes ${ }^{(13)}$.

Assim, a comunicação entre os profissionais visa firmar um vínculo que leva à construção do trabalho em equipe, na busca de responsabilizá-los e comprometê-los em relação ao paciente, e estabelecer as melhores condutas a serem seguidas ${ }^{(14)}$.

\section{Quebra de sigilo profissional, comentários e ex- posição do paciente no ambiente crítico}

A linha entre o comportamento inapropriado e/ ou o que fere os princípios éticos é frágil e tênue. Infelizmente, é possível nos depararmos com comportamentos inadequados na área da saúde. Essa situação pode influenciar na banalização da vida humana.

A questão referente ao sigilo profissional e à confidencialidade sobre informações dos pacientes hospitalizados também foi considerada pelos participantes um problema ético e, segundo os entrevistados, o sigilo nas relações profissionais é fundamental para uma assistência ética, a fim de preservar a privacidade e a segurança dos pacientes.

O CEPE dedica um capítulo inteiro ao sigilo 
profissional, artigos 81 a 85 , os quais estabelecem direitos e impõem responsabilidades e proibições aos profissionais de enfermagem concernentes a esse assunto. Faz-se imprescindível destacar que o enfermeiro, na qualidade de supervisor/responsável, segundo o que dispõe o artigo 83, deve orientar toda a equipe de enfermagem acerca do sigilo profissional $^{(3)}$.

No trabalho em saúde e em todos os seus níveis de assistência, é dever do profissional de saúde não causar danos ao paciente e, portanto, deve agir para o bem do mesmo. Entende-se que os danos não se restringem às questões físicas, podem ser de ordem moral e psicológica, subjetiva como constrangimento, vergonha, medo e até a necessidade de fuga ou distanciamento visual daquele que sabe da sua condição $0^{(15)}$.

Por fim, evidencia-se que o CEPE, no artigo 12, também dispõe que é dever do profissional de enfermagem assegurar ao cliente e sua família uma assistência livre de danos decorrentes de imperícia, negligência ou imprudência ${ }^{(3)}$.

\section{Formas inapropriadas de comunicação com o paciente e com a família - desrespeito ao direito à informação}

É direito do paciente exercer sua autonomia e ter acesso a toda informação adequada para decidir e participar, quando necessário, de forma consciente sobre as condutas a que será submetido durante a hospitalização. Esse direito do paciente é disposto no artigo 18 do CEPE, como dever do profissional de enfermagem, no artigo de respeitar, reconhecer e realizar ações que garantam o direito da pessoa ou de seu representante legal, incluindo a tomada de decisões sobre a sua saúde, tratamento, conforto e bem-estar ${ }^{(3)}$.

$\mathrm{O}$ respeito à autonomia implica em tornar as pessoas capazes de agir autonomamente, ao passo que o desrespeito envolve atitudes que ignoram decisões autônomas autênticas. Esse princípio ético preconiza que o indivíduo tem condições de pensar, decidir e agir de modo independente, e lhe é de direito participar e consentir sobre as decisões que dizem respeito à sua pessoa ${ }^{(12)}$.

Ainda, o CEPE, no artigo 26, discorre que um dos deveres dos profissionais é informar o paciente e a família acerca da assistência de enfermagem, riscos, benefícios e consequências que podem ocorrer $^{(3)}$. Prossegue, no artigo 27, dizendo que o profissional deve respeitar o direito do paciente de decidir sobre si, seu tratamento e seu bem-estar ${ }^{(3)}$.

Nesse contexto, os profissionais de enfermagem estão mais próximos dos pacientes e têm a possibilidade de acompanhar seus desejos e expectativas relacionadas ao tratamento. Essa proximidade gera um vínculo que estabelece um poder paralelo de influência e contribui no exercício de sua autonomia.

Ao respeitar o direito às informações e às decisões dos pacientes e familiares, a autonomia é concretizada no ato de cuidar; do contrário, violase esse princípio. Ressaltamos que o exercício da autonomia é facilitado quando as deliberações dos pacientes e familiares coincidem com as da equipe; nos casos de discordância, a autonomia pode estar em risco $^{(16)}$.

A Enfermagem reconhece a necessidade da presença da família no dia a dia do paciente hospitalizado e o benefício que essa proximidade proporciona à dimensão emocional do doente. Quanto mais a autonomia é considerada na discussão do quadro do paciente, mais ações humanizadas serão agregadas ao tratamento ${ }^{(16)}$.

\section{Dificuldade na distribuição adequada de recursos na assistência}

A ética preconiza o respeito às diferenças individuais, buscando alternativas para atendê-las, à liberdade de expressão e à consideração igualitária dos interesses dos pacientes e profissionais. Os profissionais acreditam que, quando os recursos disponíveis são utilizados de forma inadequada, contrariam a ética e o princípio da justiça, já que o segundo significa uma distribuição justa e universal dos benefícios dos serviços de saúde ${ }^{(17)}$.

A tomada de decisão envolvida na alocação de recursos compreende um processo complexo. O princípio da justiça faz com que os profissionais de saúde reflitam sobre a importância dos aspectos econômicos na assistência à população. Nesse contexto, uma contribuição específica da ética é possibilitar uma administração dos recursos de forma equitativa para compensação das desigualdades sociais existentes.

Como os recursos necessários, por vezes, são escassos, é preciso a definição de critérios para o atendimento das demandas. No campo da saúde, essa questão diz respeito a atendimentos que podem determinar a vida e a morte das pessoas ${ }^{(18)}$, consti- 
tuindo-se uma condição que precisa ser refletida.

\section{CONSIDERAÇÕES FINAIS}

A identificação dos principais problemas éticos vivenciados pela equipe de enfermagem que compôs este estudo permitiram evidenciar os conflitos e desafios que permeiam a prática de cuidados ao paciente crítico.

Os problemas relatados foram considerados pela maioria dos entrevistados como situações que geram desconforto para o profissional e que de alguma forma possam trazer prejuízos à assistência ao paciente e família. A equipe de Enfermagem revelou sua crença no respeito ao bem-estar do paciente, a sua individualidade e seus direitos, mas reconhece a existência desses problemas como fatores que contribuem para que muitas vezes esses direitos sejam desrespeitados.

Considerando que o reconhecimento desses problemas representa um primeiro passo para conduzir eticamente essas questões, já que por vezes não se percebe ou se fica alheio à tais dúvidas, as atitudes de problematizar, sensibilizar e refletir a partir da perceção dos conflitos do cotidiano constituem uma postura de sujeitos éticos, posto que a Ética compreende a reflexão das coisas como são e de como elas poderiam ser., podem não ser percebidos ou ficarem alheios ao contexto da prática.

Nessa perspectiva, acredita-se ser possível cuidar com respeito à dignidade da pessoa humana, de acordo com os princípios da ética e bioética, e reconhece-se que, por meio do cuidado ético, a Enfermagem tem muito a contribuir em benefício do ser humano.

\section{REFERÊNCIAS}

1. Bub MBC. Ética e prática profissional em saúde. Texto \& Contexto Enferm. 2005;14(1):65-74.

2. Brasil. Conselho Federal de Enfermagem (COFEN). Lei n. 7498, de 25 de junho de 1986. Dispõe sobre a regulamentação do exercício da enfermagem e dá outras providências. Diário Oficial da República Federativa do Brasil. Brasília;29 jun 1986. Seção 1:1.

3. Conselho Federal de Enfermagem (COFEN). Resolução n. 311, de 08 de fevereiro de 2007. Dispõe sobre O Código de Ética dos Profissionais de Enfermagem. Rio de Janeiro: COFEN; 2007.
4. Sugarman J, editor. Ethics in primary care. New York: McGraaw-Hill; 2000.

5. Lalande A. Vocabulário técnico e crítico da filosofia. São Paulo: Martins Fontes; 1999.

6. Toffoletto MC, Zanei SSV, Hora EC, Nogueira GP, Miyadahira AMK, Kimura M, et al. A distanásia como geradora de dilemas éticos nas unidades de terapia intensiva: considerações sobre a participação dos enfermeiros. Acta Paul Enferm. 2005;18(3):307-12.

7. Ministério da Saúde (BR). Conselho Nacional de Saúde. Diretrizes e normas regulamentadoras de pesquisa envolvendo seres humanos. Resolução n. 196, de 10 de outubro de 1996. Brasília; 1996.

8. Minayo MCS. Pesquisa social: teoria, método e criatividade. 23 ${ }^{\mathrm{a}}$ ed. Rio de Janeiro: Vozes; 2004.

9. Backes DS, Lunardi VL, Lunardi Filho WD. A humanização hospitalar como expressão da ética. Rev Latino-Am Enfermagem. 2006;14(1):132-5.

10. Brasil. Constituição da República Federativa do Brasil. Brasília: Senado; 1988.

11. Barbosa IA, Silva MJP. Cuidado humanizado de enfermagem: o agir com respeito em um hospital universitário. Rev Bras Enferm. 2007;60(5):546-61.

12. Selli L. Bioética na enfermagem. $2^{\mathrm{a}}$ ed. São Leopoldo: UNISINOS; 2005.

13. Ribeiro C, Araújo D, Mesquita E, Machado F, Carreiro J. Intedisciplinaridade no contexto hospitalar. CienteFico. 2004;1(4):106-12.

14. Carvalho KK, Lunardi VL. Obstinação terapêutica como questão ética: enfermeiras de unidades de terapia intensiva. Rev Latino-Am Enfermagem. 2009;17(3):308-13.

15. Barroso LMM, Carvalho CML, Galvão MTG, Vieira NFC, Barroso MG. Aspectos éticos da interação enfermeiro-puérpera com HIV/AIDS. DST J Bras Doenças Sex Transm. 2005;17(3):197-200.

16. Chaves AAB, Massarollo MCKB. Percepção dos enfermeiros sobre dilemas éticos relacionados a pacientes terminais em unidades de terapia intensiva. Rev Esc Enferm USP. 2009;43(1):30-6.

17. Pessini L, Barchifontaine CP. Problemas atuais de bioética. $8^{\mathrm{a}}$ ed. rev ampli. São Paulo: Loyola; 2007. 
18. Diniz D, Medeiros M. Envelhecimento e alocação de recursos em saúde. Cad Saúde Pública. 2004;20(5):1154-5. 